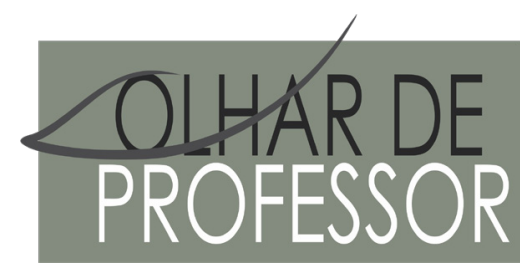

DOI: 10.5212/OLHARPROFR.v23.2020.16603.209209228763.0810

\title{
A ATUALIDADE DO PENSAMENTO DE PAULO FREIRE SOBRE AS TECNOLOGIAS: LETRAMENTOS DIGITAIS E CRÍTICOS
}

\author{
PAULO FREIRE'S PRESENT THOUGHTS ABOUT TECHNOLOGIES: DIGITAL AND CRITICAL LITERACIES \\ LA ACTUALIDAD DEL PENSAMIENTO DE PAULO FREIRE ACERCA DE LAS TECNOLOGÍAS: LITERACIDADES \\ DIGITALES Y CRÍTICAS
}

\author{
ALAN RICARDO COSTA* \\ ANDRÉ FIRPO BEVILÁQUA ** \\ VANESSA RIBAS FIALHO ${ }^{* * *}$
}

\begin{abstract}
Resumo: No presente trabalho, de caráter qualitativo, temos por objetivo debater a atualidade do pensamento de Paulo Freire no que tange às tecnologias digitais e suas potencialidades quanto às práticas educacionais. Para tanto, nossos objetivos específicos são os seguintes: (1) apresentar uma revisão da literatura quanto aos conceitos de "tecnologia" e "práxis tecnológica" na (e a partir da) obra de Freire; (2) debater os conceitos de "Letramentos Digitais" e "Letramentos Críticos", que compõem a fundamentação teórica deste estudo; e (3) apresentar e analisar, em um viés qualitativo, exemplos práticos de atividades e recursos digitais disponíveis na Web e produzidos no viés dos Letramentos Críticos. Os resultados indicam que materiais didáticos críticos disponíveis online não só mantêm atual o legado freireano, como também podem contribuir significativamente para uma educação progressistalibertadora no presente.
\end{abstract}

Palavras-chave: Paulo Freire. Letramentos Digitais. Letramentos Críticos. Cibercultura.

\begin{abstract}
The present work, which has a qualitative approach, presents as primary aim is to debate Paulo Freire's current thoughts regarding digital technologies and their potentialities concerning educational practices. Fort this purpose, our specific objectives are the following: (1) to present a literature review regarding the concepts of "technology" and "technological praxis" in (and from) Freire's work; (2) to debate the concepts of "Digital Literacies" and "Critical Literacies", which make up the theoretical framework of this study; and (3) to present and analyze, in a qualitative slant, practical examples of activities and digital resources available on the Web and produced in the perspective of the Critical Literacies. The results indicate that critical teaching materials available online not only keep the Freirean legacy as a current topic, but they may also contribute significantly to a progressive-liberating education in the present.
\end{abstract}

Keywords: Paulo Freire. Digital literacies. Critical Literacies. Cyberculture.

Resumen: En el presente trabajo, de carácter cualitativo, nuestro objetivo es debatir la actualidad del pensamiento de Paulo Freire con respecto a las tecnologías digitales y sus potencialidades con relación a las prácticas educativas. Así siendo, nuestros objetivos específicos son: (1) presentar una revisión de la literatura sobre los conceptos de "tecnología" y "praxis tecnológica" en (y desde) la obra de Freire; (2) debatir los conceptos de "Literacidades

\footnotetext{
* Doutorando do Programa de Pós-Graduação em Letras da Universidade de Santa Cruz do Sul (UNISC). E-mail: alan.dan. ricardo@gmail.com

** Doutorando do Programa de Pós-Graduação em Letras da Universidade Federal de Pelotas (UFPel). E-mail: andre.firpo@ gmail.com

*** Doutora em Letras. Professora Associada da Universidade Federal de Santa Maria (UFSM). E-mail:vanessafialho@gmail.com
} 
digitales” y "Literacidades críticas”, que constituyen la base teórica de este estudio; y (3) presentar y analizar, con sesgo cualitativo, ejemplos prácticos de actividades y recursos digitales disponibles en la Web y producidos en la perspectiva de las Literacidades Críticas. Los resultados indican que los materiales didácticos críticos disponibles en línea no solo mantienen actual el legado de Freire, sino que también pueden contribuir significativamente a una educación progresista-liberadora en el presente.

Palabras-clave: Paulo Freire. Literacidades digitales. Literacidades críticas. Cibercultura.

\section{INTRODUÇ̃̃O}

A atualidade do pensamento de Paulo Freire é inegável: a obra do legítimo Patrono da Educação Brasileira segue sendo revisitada em inúmeras pesquisas e publicações, nacionais e internacionais, nos últimos anos (e.g. ALENCAR, 2005; CASSANY; CASSTELLÀ, 2010; COSTA, 2015; COSTA; GOMES, 2018). Como exemplo, cabe mencionar a pesquisa de Costa e Gomes (2017) sobre as contribuições da obra de Paulo Freire nas práticas e ações pedagógicas de cursos pré-vestibular e/ou pré-universitário populares na atualidade. Mário Sergio Cortella (2011), quanto ao assunto, a partir de sua convivência com Freire, defende que o pensamento do grande educador recifense é clássico e atual, sem ter se emoldurado num processo de engessamento, ou seja, é um legado clássico, mas sem perda de irrigação de sua atualidade. Destarte, Paulo Freire nos anima, nos “enche de alma”, de "vida” e, nesse sentido, o seu pensamento é altamente inspirador (CORTELLA, 2011, p. 12).

Dentre os muitos tópicos que podem ilustrar a atualidade da epistemologia freireana, no presente texto, propomo-nos a debater a atual efervescência tecnológica, que não deixa de transformar radicalmente nossa educação e nossos entendimentos sobre as formas de ensinar e aprender. Referimo-nos à cibercultura, que "consiste em um conjunto de transformações epistemológicas e culturais de inúmeras ordens” (COSTA et al., 2020b, p. 30).

A cibercultura - debatida e difundida mais notoriamente pelo filósofo Pierre Lévy, e ainda carente de maiores diálogos com o pensamento de Paulo Freire - caracteriza-se por formas emergentes e complexas de ser e estar (e, por conseguinte, de pensar, agir e comunicar) no ciberespaço e no mundo (COSTA et al., 2020b, p. 17-18).

Em publicação recente (COSTA et al., 2020b), algumas primeiras aproximações entre as obras de Freire (1984; 1989) e Lévy (2010) foram esboçadas, visando às discussões sobre o papel das tecnologias digitais na educação atual. Assim, neste trabalho temos por objetivo geral dar continuidade às discussões inerentes a um dos aspectos mais ilustrativos do pensamento freireano na educação brasileira contemporânea: as tecnologias educacionais e, principalmente, a práxis tecnológica (ALENCAR, 2005). Para tanto, nossos objetivos específicos são os seguintes: (1) apresentar uma revisão da literatura quanto aos conceitos de "tecnologia" e "práxis tecnológica" na (e a partir da) obra de Freire; (2) debater os conceitos de "Letramentos Digitais” e "Letramentos Críticos”, que compõem a fundamentação teórica deste estudo; e (3) apresentar e analisar, em um viés qualitativo, exemplos práticos de atividades e recursos digitais disponíveis na Web e produzidos no viés dos Letramentos Críticos (BEVILÁQUA, 2017; BEVILÁQUA; COSTA; FIALHO, 2019).

Este artigo encontra-se estruturado da seguinte forma: inicialmente, a partir de uma revisão de literatura da área, apresentamos as noções freireanas de "tecnologia" e "práxis tecnológica". Em seguida, apresentamos conceitos de "letramento", com ênfase nas acepções de "letramentos digitais" e "letramentos críticos". Finalmente, ilustramos a atualidade do pensamento freireano a partir da apresentação de recursos digitais disponíveis na Web produzidos na perspectiva dos Letramentos Críticos. 


\section{DA TECNOLOGIA SEGUNDO PAULO FREIRE À PRÁXISTECNOLÓGICA}

Subjacente à obra de Freire está uma acepção de “tecnologia” para muito além das coisas/objetos. Assim como propunha Lévy (2010), a noção de tecnologia abarca a técnica, o humano e as compreensões sobre a tecnologia, implicando no processo uma superação da dicotomia humano/máquina. Nesse viés, a tecnologia, para Freire, é uma das "grandes expressões da criatividade humana” (FREIRE, 1968, p. 98), é expressão natural do processo criador dos seres humanos (FREIRE, 1968). A tecnologia não é obra de demônios, mas da humanidade: as tecnologias fazem parte do desenvolvimento natural de todo e qualquer ser humano (FREIRE, 1968).

A preocupação de Freire quanto às tecnologias não enfatizava o recurso ou o instrumento em si, mas as ações humanas (e, por conseguinte, políticas e ideológicas) sobre ele. Sintetiza bem esse pensamento a opinião do Patrono da Educação Brasileira quanto aos usos de computadores nas práticas educacionais e nas escolas. Defendia Freire que os computadores (e as tecnologias, de modo geral), em lugar de reduzir, poderiam expandir a capacidade crítica e criativa dos(as) estudantes. "Depende de quem usa a favor de quê e de quem e para quê” (FREIRE, 1995, p. 98).

Todo o exposto até aqui aponta para uma concepção de tecnologia que não deve ser vista de forma descuidada, sem criticidade, tampouco empregada para fins educacionais sem uma devida preparação. Na opinião de Alencar, podemos dizer que Freire delineou uma metodologia de uso e análise para todo tipo de tecnologia que venha a ser incorporada nas práticas educacionais (ALENCAR, 2005, p. 3). Tal metodologia, que conceberemos enquanto uma "práxis tecnológica" freireana, conta com pelo menos quatro princípios, por assim dizer, sobre os quais passamos a dissertar a seguir, com base em Alencar (2005).

1. O primeiro princípio para uma práxis tecnológica trata dos usos intencionais e políticos da tecnologia (COSTA et al., 2020b). Já sabemos que todo uso da tecnologia está imbuído de ideologia, e não se pode negligenciar isso. Como aparato ideológico, todo e qualquer recurso técnico deve ser desconstruído e revisado nas suas "entranhas”. Quer dizer,

É preciso identificar o que fundamenta práticas e usos tecnológicos, para combatê-las ou mesmo reverter seu uso para as causas a que se defende. E isso é extremamente importante porque até a construção de softwares, páginas da web ou aplicativos são baseados em uma certa concepção de mundo, de homem ou de ensino e aprendizagem (ALENCAR, 2005, p. 3).

"Esse primeiro princípio destaca, em suma, a importância de não sermos ingênuos quanto à tecnologia” (COSTA et al., 2020b, p. 57). A ideia de que a tecnologia vem de algum lugar de fora, noção fortemente criticada por Lévy (2010), se relaciona a essa "ingenuidade":

As tecnologias não vêm de fora, de algum lugar externo; são os seres humanos que as desenvolvem e as usam. Por conseguinte, como nos lembra Freire, temos que pensar nos objetivos por trás dessas tecnologias, temos que cuidar as intencionalidades que moveram os seres humanos que as produziram (COSTA et al., 2020b, p. 57).

2. O segundo princípio para uma práxis tecnológica refere-se à necessidade de se compreender, controlar e dominar a tecnologia. Freire (1977, p. 129), parafraseando o escritor estadunidense Harry Braverman (1920-1976), em seu livro mais famoso, Labor and Monopoly Capital - The degradation of work in the twentieth century, defendia que, para se usar os aparatos tecnológicos, era preciso compreender a sua razão de ser (COSTA et al., 2020b). Os trabalhadores e as trabalhadoras não podem ser alienados(as) quanto a esse uso, como se fossem máquinas irracionais (ALENCAR, 2005).

Um exemplo pertinente para essa questão são os próprios docentes, enquanto trabalhadores (profissionais da educação), atuantes em cursos online (tão populares na cibercultura) e presenciais também (COSTA et al., 2020b). Tais docentes não podem ser reduzidos ao papel de máquinas que somente realizam movimentos repetitivos, sem a mínima noção do que fazem ou do que produzem, trabalhadores hiper-especialistas. Entender o processo é de fundamental importância, advoga Paulo Freire, porque conduziria os homens e as mulheres à humanização, a deslocar-se de uma concepção do meio como suporte, para a ideia de mundo possível, isto é, passível de transformação, evitando assim, a “maquinização” ou animalização instintiva dos seres humanos (ALENCAR, 2005). Paulo Freire assegurava: "Quando se diz ao educador 
como fazer tecnicamente uma mesa e não se discute as dimensões estéticas de como fazê-la, castra-se a capacidade de ele conhecer a curiosidade epistemológica” (FREIRE; PASSETI, 1994-1995, p. 87).

3. O terceiro princípio para uma práxis tecnológica é a imperativa redução sociológica (COSTA et al., 2020b). Paulo Freire temia e acreditava que, em variadas circunstâncias, inovações tecnológicas têm sido impostas na direção "de cima para baixo”, de forma nada dialógica ou democrática (ALENCAR, 2005). Esse fenômeno tecnológico também poderia ser caracterizado como imposição no sentido "de fora para dentro”, configurando, por conseguinte, uma verdadeira invasão cultural (FREIRE, 1976, p. 24). Para o Patrono da Educação Brasileira, toda tecnologia tem de ser compreendida. Para tanto, ela deve, primeiramente, ser contextualizada, isto é, contextualizar a tecnologia em si própria, sua gênese e utilização, desvelando os interesses e as ideologias implícitas, os benefícios e as limitações do uso (ALENCAR, 2005).

Além disso, em seguida, a tecnologia deve ser identificada, no sentido de identificação com o contexto local, discutindo suas implicações na vida dos usuários ativos e a melhor forma de incorporá-la para o bem daquele grupo, naquele contexto. No caso das tecnologias educacionais, devemos identificar a tecnologia ao pensarmos a melhor forma de incorporá-la em métodos e abordagens para o bem de um grupo discente em um determinado contexto (escolar, universitário, de educação popular ou não-formal etc.) (COSTA et al., 2020b, p. 59-60).

4. O quarto e último princípio, para uma possível práxis tecnológica no viés de Freire, é a atitude assumida diante da tecnologia. Paulo Freire advogava que nossa atitude deve ser criticamente curiosa, indagadora, crítica, vigilante (ALENCAR, 2005), e que devemos sempre refletir sobre ela:

O que me parece fundamental para nós, hoje, mecânicos ou físicos, pedagogos ou pedreiros, marceneiros ou biólogos é a assunção de uma posição crítica, vigilante, indagadora, em face da tecnologia. Nem, de um lado, demonologizá-la, nem, de outro, divinizá-la (FREIRE, 1992, p. 133).

Com base em Costa et al. (2020b), o foco, então, é usar a tecnologia, e não ser usado ou manipulado docilmente como objeto por ela. Não que a tecnologia "tenha vida por si própria, mas ela pode ser usada para manipular e estar a serviço de uma concepção de mundo que não é emancipadora” (ALENCAR, 2005, p. 4). Não podemos ser objetos de comunicados ou consumidores ávidos de pacotes tecnológicos; Freire (1996, p. 139), referindo-se à TV ${ }^{1}$, insiste que "devemos usá-la, sobretudo, discuti-la”.

Para deixar mais explícita essa discussão e tencionar o debate, é possível apropriar-se de algumas reflexões tecidas por Freire no conjunto de sua obra, principalmente em A Pedagogia da Indignação e em A máquina está a serviço de quem?:

[...] o exercício de pensar o tempo, de pensar a técnica, de pensar o conhecimento enquanto se conhece, de pensar o quê das coisas, o para quê, o como, o em favor de quê, de quem, o contra quê, o contra quem são exigências fundamentais de uma educação democrática à altura dos desafios do nosso tempo (FREIRE, 2000, p. 102).

"Diferentes pesquisadores já abordaram em seus estudos essas preocupações freireanas acerca de curiosidade necessária aos usos das tecnologias” (COSTA et al., 2020b, p. 61). Calado (2001), por exemplo, também citado por Alencar (2005), destaca a preocupação de Freire sobre a importância de um olhar constantemente curioso e crítico sobre a tecnologia:

[...] ao acolher positivamente os avanços tecnológicos, [Freire] nunca abdicou de fazê-lo, de modo crítico, a exemplo de como se posiciona frente à utilização de novas tecnologias, no caso específico da penetração da informática nas escolas: ‘Já disse que faço questão de ser um homem do meu tempo. O problema é saber a serviço de quem, e de quê, a informática estará agora maciçamente na educação brasileira’ (CALADO, 2001, p. 27).

\footnotetext{
${ }^{1}$ No referido trecho da Pedagogia da Autonomia, Freire não se refere à televisão por si só, ou como tecnologia apenas, mas também abarca o papel da mídia em geral e as comunicações como um todo, que nunca são neutras (COSTA et al., 2020b, p. 60).
} 
Essa práxis tecnológica aqui tratada, com base em pressupostos teórico-metodológicos esquematizados por Alencar (2005) a partir do legado de Paulo Freire, evidentemente, “não compõe um método a ser seguido à risca, como um manual ou uma receita” (COSTA et al., 2020b, p. 62). Essa práxis é

na melhor das hipóteses, um conjunto de aspectos a ser considerado por educadoras e educadores em suas realidades sociais, suas escolas, seus contextos de trabalho docente, não da mesma forma como fez Freire, pois isso já não é possível: as tecnologias que ele testemunhou e usou já não são mais as mesmas, assim como o cenário educacional brasileiro já não é o mesmo de décadas atrás (COSTA et al. 2020b, p. 62).

A reflexão sobre o uso político da tecnologia, sua compreensão, controle e domínio, assim como a curiosidade sobre ela, e a atitude assumida frente a ela, devem estar em constante atualização, acompanhando a cibercultura (LÉVY, 2010) na qual estamos inseridos (COSTA et al., 2020b).

\section{LETRAMENTOS, LETRAMENTOS DIGITAIS E LETRAMENTOS CRÍTICOS}

Os Novos Estudos de Letramentos (NEL), que têm em Paulo Freire uma das referências mais importantes, compreendem as múltiplas facetas da linguagem em diversas formas multimodais, "bem como seus usos em diferentes contextos históricos e sociais e as relações existentes entre o sujeito produtor, consumidor e distribuidor de textos" (PINTO, 2015, p. 26).

Em uma perspectiva sociocultural, considera-se que "os letramentos são práticas sociais e culturais, pois irão fazer sentido dentro de um grupo social, que partilha visões de mundo, culturas, modos de ser e agir, valores e que possuem uma coesão na sua identidade” (PINTO, 2015, p. 29). E, dentre os estudos linguísticos desenvolvidos no Brasil na última década, as discussões sobre os Letramentos Digitais têm ocupado local de destaque. Afinal,

A nova realidade social, devido ao crescente uso das mídias, da Internet, de aparelhos móveis e da invasão das imagens no espaço público e privado, requer uma aprendizagem de letramentos em que os modos de comunicação não se limitem apenas à linguagem verbal (PINTO, 2015, p. 39).

Em sua tese de doutorado referente à agenda de pesquisa brasileira sobre letramento digital, a partir de uma pesquisa qualitativa, Pinto (2015) discorre sobre o Modelo 3D. Tal modelo, que nasce na obra de Durrant e Green (2001), é assim chamado por contemplar as três dimensões do letramento digital, quais sejam:

(1) a dimensão operacional, que se refere à competência com o sistema da linguagem. Inclui - mas vai além - da competência técnica de saber como operar uma tecnologia. "Enfatiza-se como sujeitos individualmente e apropriadamente são capazes de ler, ver, ouvir, escrever, falar, isto é, operar efetivamente em contextos específicos com objetivos próprios” (PINTO, 2015, p. 43);

(2) a dimensão cultural, que envolve competência com o sistema de sentido, ou melhor, é uma maneira de compreender os textos e a tecnologia em relação aos contextos em que estão inseridos, pois cada um implica em um conteúdo específico,

O que faz com que haja maneiras apropriadas ou inapropriadas de escrever, ler, compartilhar, ver, falar e ouvir. Isso inclui também habilidades para o uso de textos - configurados em gêneros discursivos - adequados em cada contexto e os vários modos de comunicação como livros, correio eletrônico, mídia impressa e eletrônica, internet (PINTO, 2015, p. 43).

(3) a dimensão crítica, por sua vez, é concernente à natureza socialmente construída das práticas humanas. Para ser capaz de participar efetivamente e produtivamente de qualquer prática social, o sujeito deve socializar-se e desenvolver competências para transformar e produzir ativamente uma prática (PINTO, 2015). Esse aspecto transformacional dos letramentos inclui capacidades de compreender e imbuir os textos de sentido, dependendo do lugar social que o leitor ocupa ao ler o texto, criticá-lo, (re) 
apropriá-lo e redesenhá-lo. "Está também relacionado com contexto, história e poder, por isso leva-se em consideração que o conhecimento é sempre parcial e seletivo” (PINTO, 2015, p. 44).

Talvez pela importância de não negligenciar a dimensão crítica dos letramentos, de modo geral que, em paralelo ao aumento dos estudos sobre letramento, nas últimas décadas têm crescido também o interesse, na Linguística Aplicada (LA), pelas pesquisas sobre os Letramentos Críticos (COSTA et al., 2020a). Ao passo que os letramentos podem ser entendidos resumidamente como "práticas sociais de leitura e de escrita mais avançadas e complexas que as práticas do ler e do escrever resultantes da aprendizagem do sistema de escrita” (SOARES, 2004, p. 6), os “Letramentos Críticos” seriam um enquadramento crítico dessas práticas, isto é, um esforço por colocar linguagens e suas tecnologias a serviço de setores socialmente marginalizados (BEVILÁQUA, 2017; COSTA et al., 2020b). De acordo com Cassany e Castellà (2010), embora o conceito de criticidade costume ser atribuído aos teóricos da Teoria Crítica, o responsável por sua aplicação ao campo do letramento foi Paulo Freire. Nas palavras dos autores:

Dito conceito foi aplicado ao campo do letramento nos anos sessenta pelo famoso pedagogo brasileiro Paulo Freire, que formulou com clareza a ideia de que os analfabetos são vítimas e não responsáveis de sua condição, que a escola é uma instituição criada por determinados grupos sociais para reproduzir o status quo (a pedagogia da opressão) e que o acesso ao letramento pode ser uma ferramenta importante de libertação ou empoderamento dos indivíduos. Ao aprender a ler, os sujeitos obtêm poder (“empoderam-se”) e podem transformar a realidade injusta que os rodeia (CASSANY; CASTELLÀ, 2010, p. 358)².

Quanto ao papel das linguagens, ainda que a maior parte das teorizações de Freire tenha ficado circunscrita ao recurso semiótico da escrita, com apenas alguns insights ${ }^{3}$ com relação a outras semioses, entendemos que o pedagogo brasileiro foi um dos precursores em trazer à tona a relação entre "linguagem e realidade”, entre "texto e contexto" (BEVILÁQUA, 2017; COSTA et al., 2020b). Além disso, Freire também foi um dos pioneiros a considerar o papel da Educação, em geral, e da linguagem, em específico, para a transformação do status quo de uma sociedade injusta e desigual (BEVILÁQUA, 2017).

\section{RECURSOS DIGITAIS E ATIVIDADES NO VIÉS DOS LETRAMENTOS CRÍTICOS}

A proposta de materiais, recursos e atividades didáticas na linha dos Letramentos Críticos (BEVILÁQUA, 2017; COSTA et al., 2020b) parte da ideia de que a produção destes deve levar em consideração uma pedagogia desenvolvida pelo(a) próprio(a) educador(a), a partir de particularidades políticas, culturais, sociais e linguísticas (KUMARAVADIVELU, 2006). "O papel dos Letramentos Críticos, nesse contexto, é oferecer insumos teórico-metodológicos que poderão auxiliar no desenvolvimento dessa pedagogia” (COSTA et al., 2020b, p. 83). Certamente, pode-se argumentar que uma limitação, nessa perspectiva dos Letramentos Críticos, seria a necessidade de mais dedicação de educadores(as) para a produção do material didático ou desenvolvimento da atividade, o que pode ser complicado em alguns contextos e espaços com pouca infraestrutura ou investimento nesse tipo de trabalho docente (COSTA et al., 2020b). Entendemos, contudo, que é necessário investir nessa perspectiva crítica, apesar das adversidades: "o caminho pode ser árduo, mas é necessário; uma práxis docente no viés freireano não deixa espaço para omissões” (COSTA et al., 2020b, p. 83).

Haja vista as considerações e reflexões tecidas até aqui, passamos a apresentar algumas atividades e recursos desenvolvidos à luz da Pedagogia Crítica e dos Letramentos Críticos (BEVILÁQUA; COSTA; FIALHO, 2019), tanto de nossa autoria quanto da autoria de educadores(as) que participaram de algumas formações (como disciplinas, cursos e oficinas de capacitação) que oferecemos sobre o assunto (COSTA et al., 2020b). Alguns desses materiais podem ser acessados para uso e/ou adaptação no sistema ELO, sigla para Ensino de Línguas Online (LEFFA, 2016). O ELO é um Sistema de Autoria Aberto (SAA)

\footnotetext{
${ }^{2}$ Tradução de Costa et al. (2020b), grifos dos autores.

${ }^{3}$ Segundo Costa et al. (2020b), a modo de exemplo, na obra A importância do ato de ler, Freire (1989) descreve algumas atividades envolvendo linguagem escrita e fotografias.
} 
gratuito e disponível de forma totalmente em rede (em nuvem) para educadores e educadoras produzirem atividades e materiais didáticos das mais variadas áreas e campo do saber ${ }^{4}$.

A primeira atividade que gostaríamos de apresentar chama-se Aquí se respira lucha. Esse material disponível no ELO foi elaborado para o ensino de Espanhol como Língua Estrangeira (ELE), levando em consideração os seguintes módulos: hipertexto, sequência, eclipse, memória, cloze, quiz (múltipla escolha), vídeo e composer e composer 5 . De acordo com Leffa (2016), os módulos são as partes que compõem uma atividade, mais ou menos como funciona com um jogo de Lego, porém com peças cuja plasticidade é infinitamente maior. Apresentamos, a seguir, o primeiro módulo da atividade, isto é, o hipertexto:

FIGURA 1: MÓDULO HIPERTEXTONO ELO, २०२०

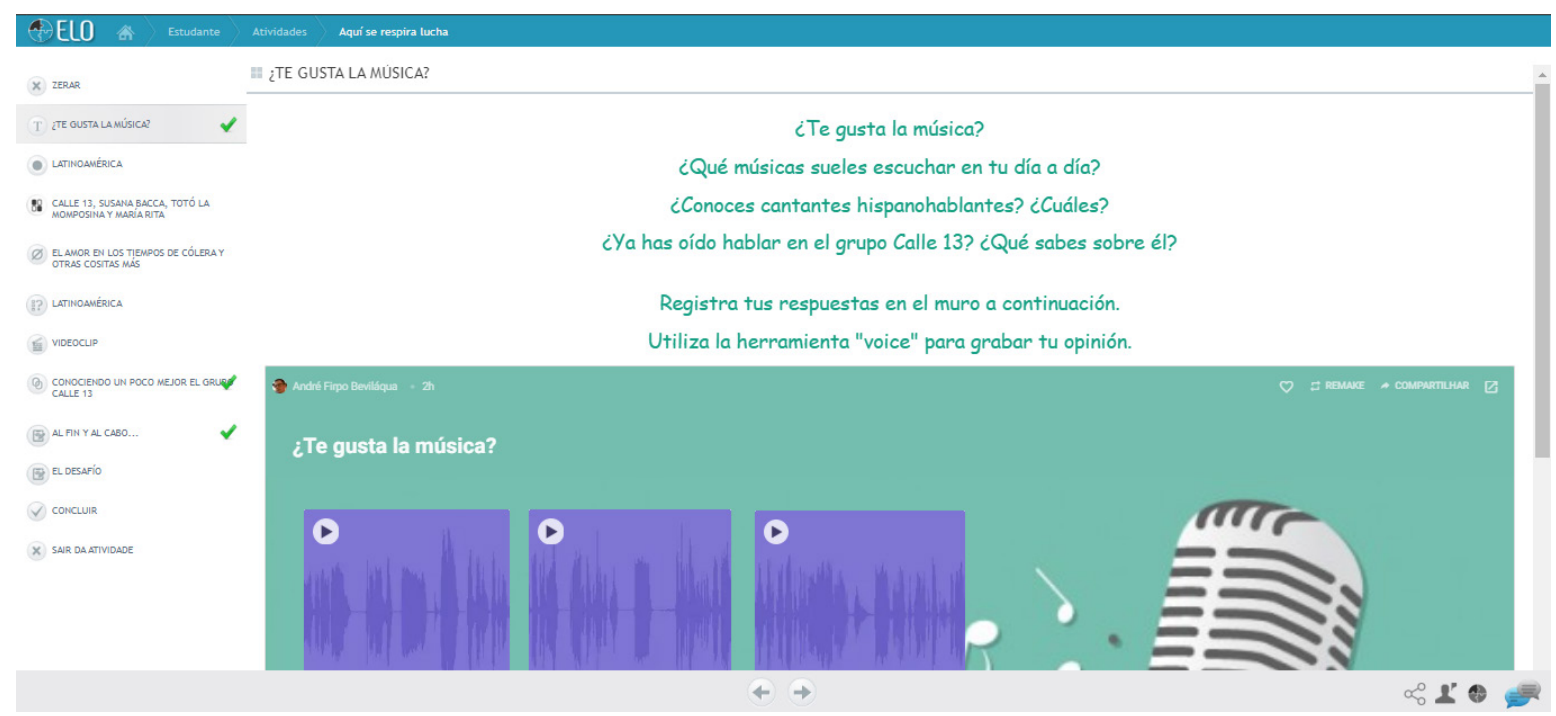

FONTE: OS AUTORES, २०२०

Conforme podemos observar na Figura 1, o módulo hipertexto apresenta algumas perguntas em língua espanhola, com vistas a resgatar os saberes prévios dos(as) educandos(as) sobre o assunto da atividade. Em seguida, há um espaço no qual tais aprendizes podem registrar suas respostas oralmente, conforme solicitado pelo enunciado da tarefa. Esse espaço foi construído a partir da incorporação de outra ferramenta no ELO, a qual pode ser utilizada tanto para o ensino de línguas quanto para outras áreas do conhecimento. Essa ferramenta chama-se Padlet ${ }^{6}$ e propicia a elaboração de mapas mentais e murais colaborativos multimodais (linguagem escrita, imagens, áudios, vídeos etc.). Após registrar as respostas oralmente, os(as) educandos(as) podem utilizar o menu à esquerda (ou também as setas na barra inferior da tela) para avançar na atividade.

Os módulos posteriores facilitam a compreensão da música Latinoamérica, do grupo porto-riquenho Calle 13. Essa canção não apenas conta com a participação de três ícones da música latino-americana a saber, Maria Rita (Brasil), Totó la Momposina (Colômbia) e Susana Baca (Peru) - como também faz alusão a questões históricas, políticas e culturais dessa extensa região do continente Americano. Ao longo da música, identificamos, por exemplo, versos que fazem alusão à obra literária El amor en los tempos del cólera, de Gabriel García Márquez (Colômbia), ao jogador de futebol Diego Maradona (Argentina), à Operação Condor (Brasil, Argentina, Chile, Bolívia, Paraguai e Uruguai), entre outros elementos pertinentes à cultura latino-americana. Todos esses elementos podem levar à constante reflexão crítica sobre uma identidade latino-americana, não de forma estereotipada, que recairia na lógica colonial, mas de

\footnotetext{
${ }^{4}$ Embora seja um projetado mais direcionado às demandas de professores de línguas, hoje, o repositório já conta com a presença virtual e a produção didática de docentes de áreas como Geografia, Matemática, Biologia, entre outras. O ELO está disponível em <https://elo.pro.br/cloud/>. Para mais informações, ver Leffa (2016) e Beviláqua, Costa e Fialho (2019).

${ }^{5}$ No ELO, um mesmo módulo pode ser explorado de diferentes maneiras. Isso explica por que, nas atividades apresentadas a seguir, alguns módulos se repetem.

${ }^{6}$ Padlet < disponível em https://padlet.com/>.
} 
forma complexa, no fluxo constante de perturbações, transgressões e subversões de identidades existentes, perspectiva já registrada por Urzêda-Freitas (2012), com base nos estudos culturais, na Linguística Aplicada Crítica (LAC) e na obra de Paulo Freire.

Um exemplo de como a compreensão da música é conduzida pela atividade é apresentado na Figura 2:

FIGURA 2: DUAS IMAGENS REFERENTES AO MÓDULO CLOZE NO ELO, २०२०.

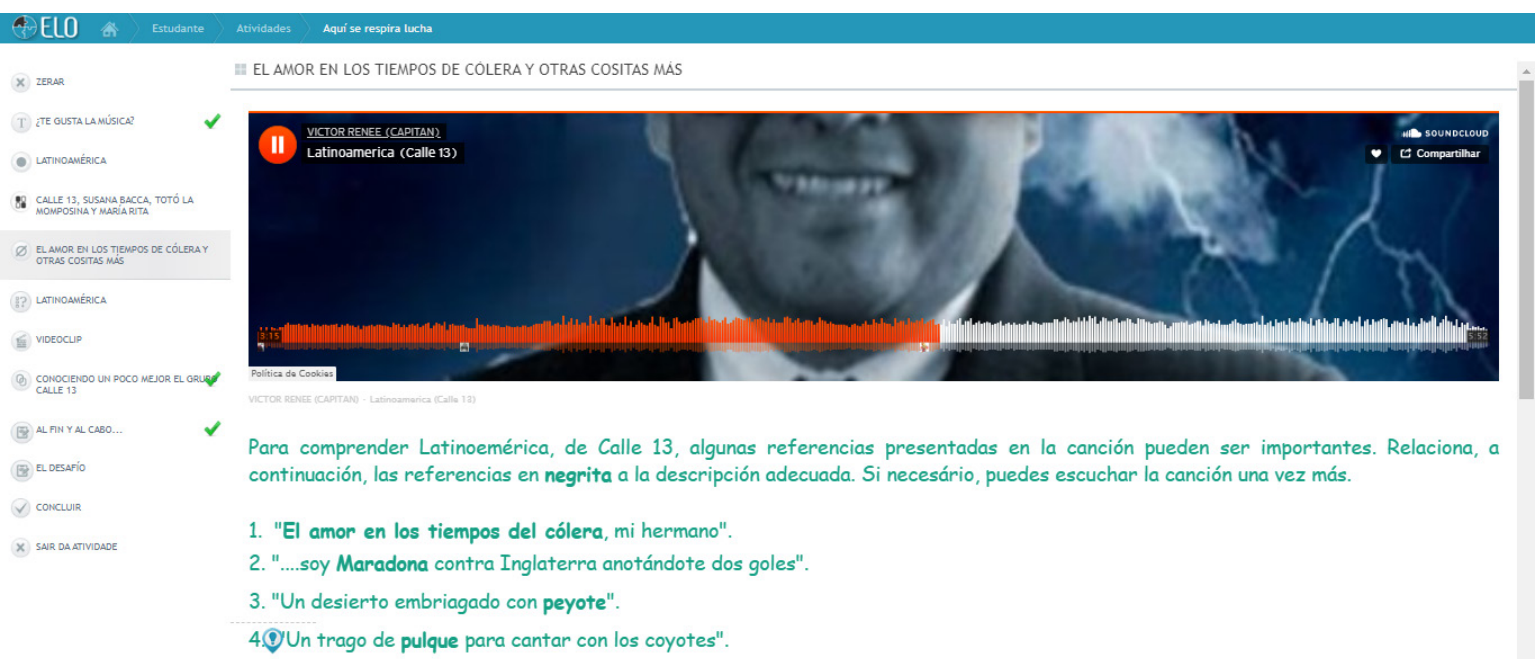

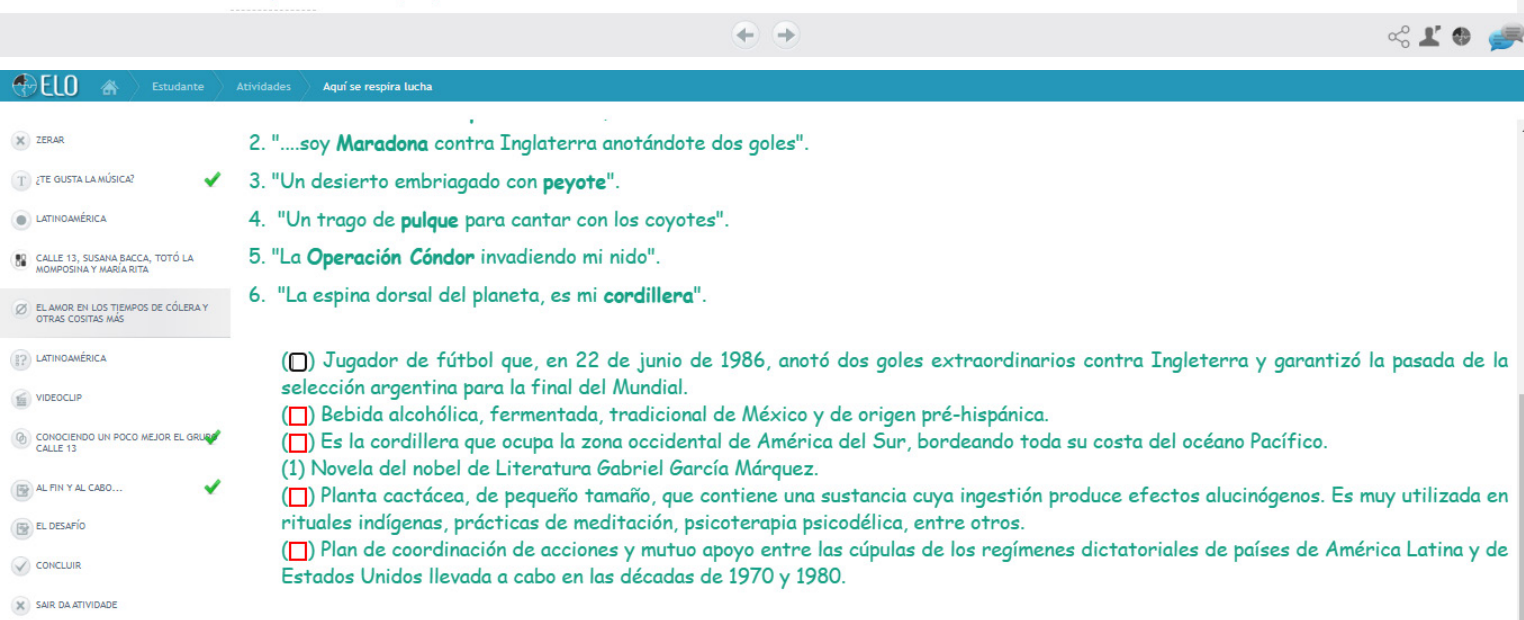

FONTE: OS AUTORES, 2020

Na Figura 2, o módulo cloze solicita que os(as) estudantes relacionem algumas das referências históricas, políticas e culturais da música Latinoamérica a suas respectivas definições - "Amor en los tiempos del cólera” (lista numerada) e "Novela del nobel de Literatura Gabriel García Márquez" (definição), por exemplo. Essas questões, assim como outras relativas ao contexto de produção, distribuição e consumo (FAIRCLOUGH, 2008) da música, e às características dessa prática social, também são problematizadas no decorrer da atividade. Ao final, pede-se que o(a) educando(a) escreva um comentário sobre Latinoamérica, para posterior publicação no canal do YouTube do grupo Calle 13.

A segunda atividade que gostaríamos de apresentar chama-se Stickermania. Esse material também está disponível no ELO e foi produzido para o ensino de Português como Língua Materna (PLM), explorando os seguintes módulos: hipertexto, cloze, quiz, composer, organizador, memória, cloze, composer e hipertexto. Apresentamos, na Figura 3, o primeiro módulo da atividade: 


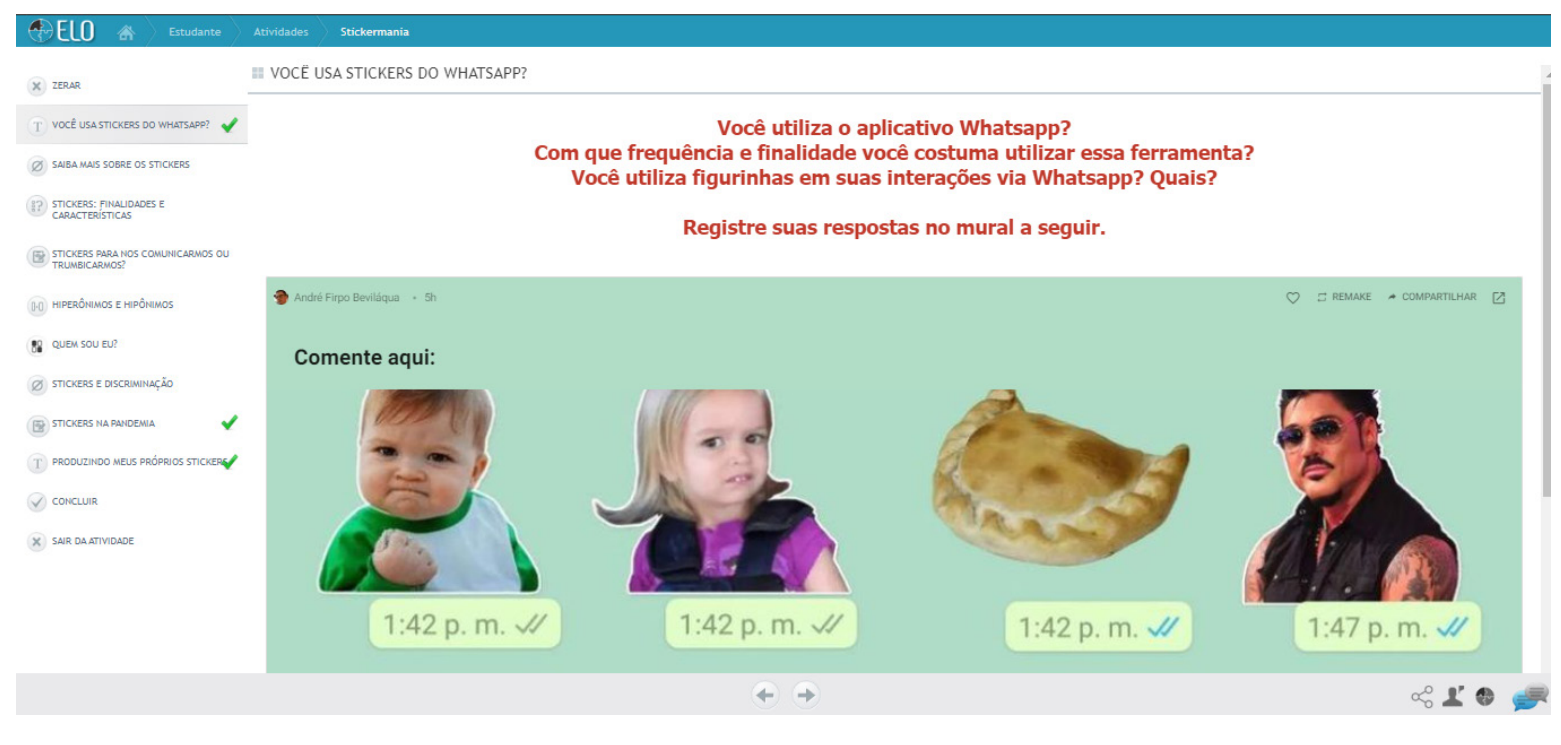

FONTE: OS AUTORES, 2020

Conforme podemos observar, a atividade Stickermania, da mesma forma que a anterior, inicia com um hipertexto, que resgata os saberes prévios dos(as) educandos(as), por meio da incorporação de um mural do Padlet. Chama a atenção, porém, que o hipertexto da Figura 3 apresenta diferenças substanciais com relação ao da atividade anterior (Figura 1), tanto no que tange ao conteúdo das perguntas quanto no que diz respeito aos aspectos técnicos, como cor e estilo da fonte, plano de fundo do mural, modo de registro do conhecimento prévio do(a) estudante (antes era na modalidade oral, agora é na modalidade escrita) etc. 
Após a conclusão do módulo, o(a) educando(a) pode avançar a atividade, com auxílio do menu à esquerda ou das setas localizadas na barra inferior da tela. Nos módulos seguintes, a atividade facilita a compreensão e a produção da prática social stickers de WhatsApp, conforme ilustra a Figura 4:

FIGURA 4: IMAGENS REFERENTES AO MÓDULO ORGANIZADORNO ELO, २०२०

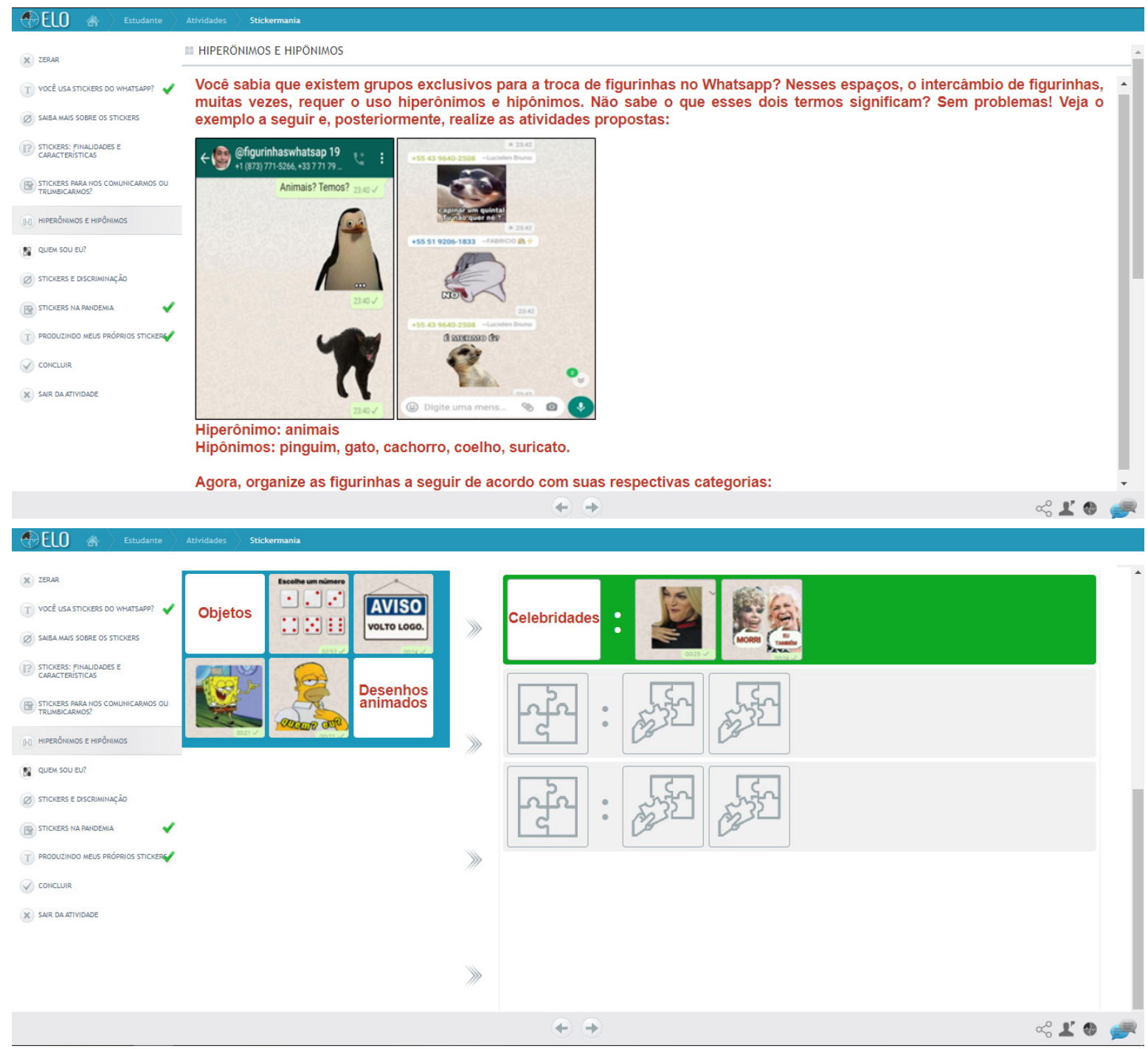

FONTE: OS AUTORES, 2020

No decorrer dos módulos, além das características dos stickers e do contexto de produção, distribuição e consumo (FAIRCLOUGH, 2008) dessa prática social, também são discutidas questões linguísticas como hiperonímia e hiponímia, conforme ilustra a Figura 4. Nesse módulo, os(as) educandos(as) são convidados(as) a refletir sobre a importância de tais questões para uma participação mais efetiva em práticas sociais como a troca de figurinhas em grupos do Whatsapp. 
Apresentamos, na Figura 5, mais um módulo da atividade: o cloze:

FIGURA 5: MÓDULO CLOZE NO ELO, २०२०.

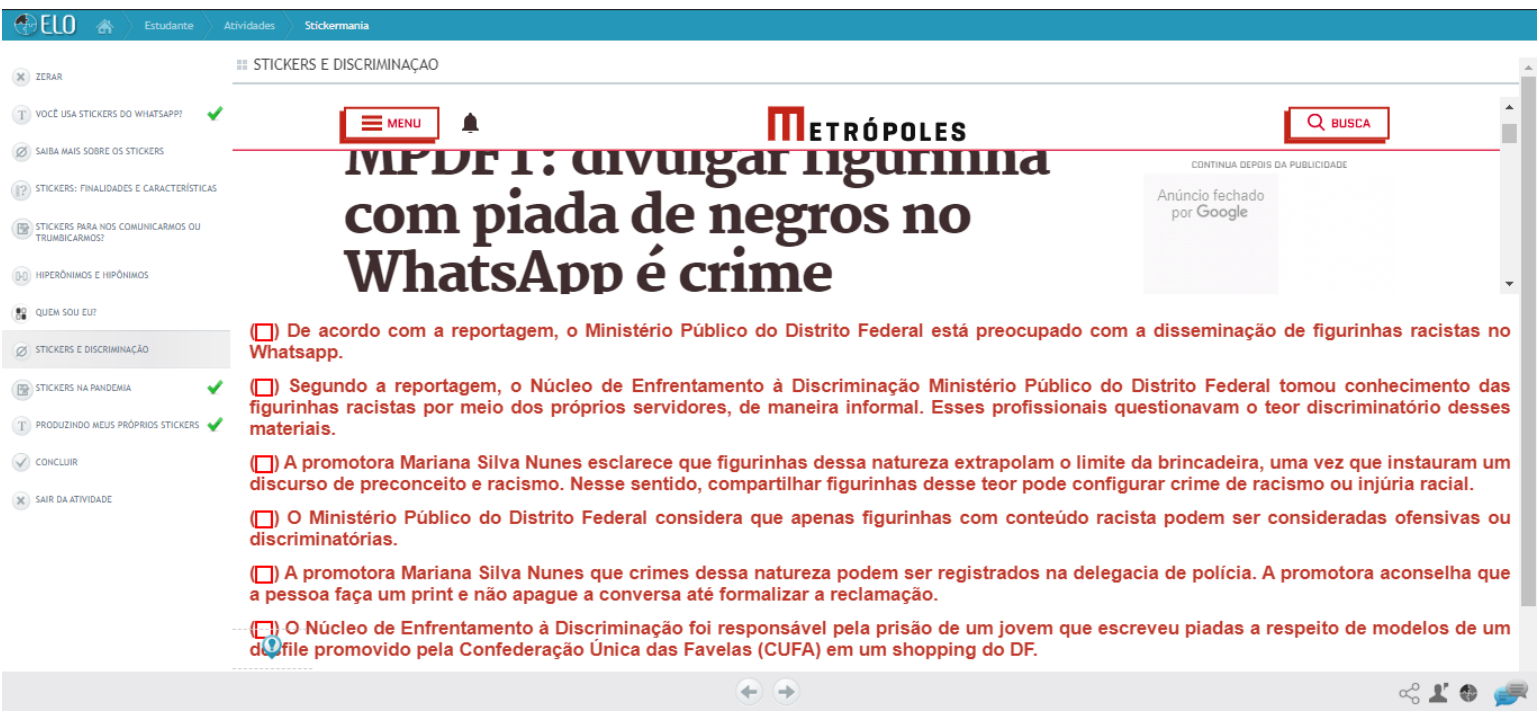

FONTE: OS AUTORES, 2020

A atividade com o módulo cloze discute, ainda, o papel dos stickers para a manutenção ou para a transformação do status quo de questões sociais, como o racismo. Lembrando a motivação de UrzêdaFreitas (2012, p. 80) de levar os aprendizes "a utilizar a língua-alvo para refletir sobre temas de caráter político-social, tais como classe, raça, etnia, gênero, sexualidade etc.”, assim como sugere Ferreira (2006; 2014) em sua perspectiva crítica e anti-racista para o ensino de línguas. O racismo segue como um dos problemas mais urgentes da sociedade em que estamos inseridos, e segue causando "sofrimento às pessoas, tornando-as vítimas do preconceito e da exclusão” (Urzêda-Freitas, 2012, p. 92). Um trabalho alicerçado nos Letramentos Críticos é fundamental numa educação antirracista, tão almejada no cenário atual, e a atividade Stickermania, a exemplo disso, tem como escopo essa questão racial7.

Na Figura 5, por exemplo, o módulo cloze trata de uma reportagem a respeito de uma preocupação recente do Ministério Público do Distrito Federal: a disseminação de stickers racistas no Whatsapp. Esse módulo, porém, vai além da constatação de que os stickers podem instaurar um discurso racista, pois chama a atenção para possíveis consequências de práticas desse tipo na internet.

\footnotetext{
${ }^{7}$ Estudos futuros, a serem realizados com a implementação e a avaliação da aprendizagem de línguas a partir da referida atividade, podem averiguar a contribuição do material na prática do "letramento racial crítico” (FERREIRA, 2014).
} 
Ao final da atividade, os(as) educandos(as) são convidados(as) a produzirem seus próprios stickers, com auxílio da ferramenta Sticker.ly. Um tutorial sobre o uso dessa ferramenta é incorporado ao ELO, por meio de um hiperlink, conforme ilustra a Figura 6.

FIGURA 6: MÓDULO HIPERTEXTONO EL0, २०२०.

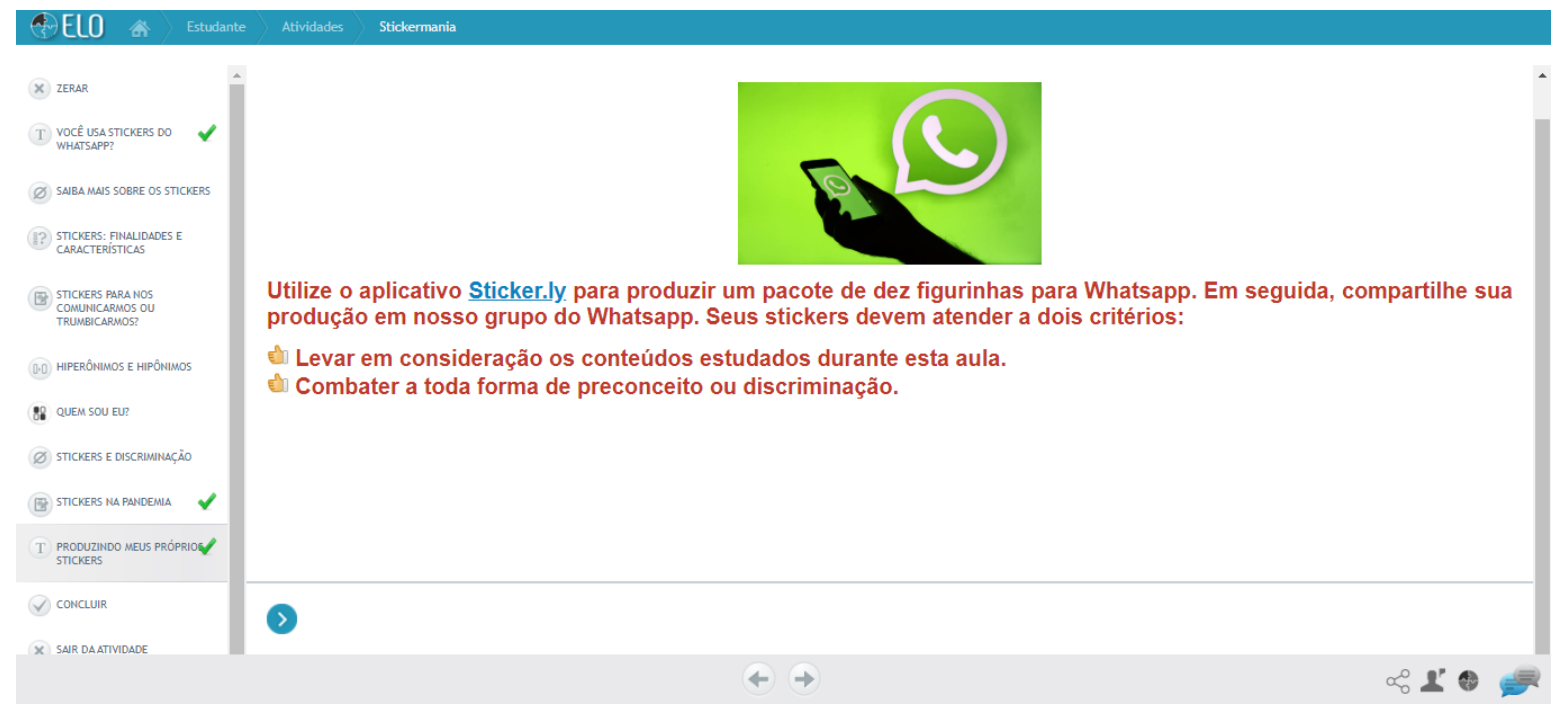

FONTE: OS AUTORES, 2020.

Do nosso ponto de vista, tanto a atividade Aquí se respira lucha quanto a Sticker mania vem ao encontro da concepção de Letramentos Críticos com a qual temos operado nos últimos tempos: uma abordagem transdisciplinar "cujo propósito principal é o de colocar linguagens e suas tecnologias a serviço de uma ética mais responsiva à sociedade contemporânea, sobretudo com relação às questões de gênero, raça, classe, entre outras” (BEVILÁQUA; COSTA; FIALHO, 2019, p. 310). Tal perspectiva, conforme discutimos em pesquisas recentes sobre o assunto (e.g. BEVILÁQUA, 2017; COSTA, et al., 2020b), possui em suas raízes a Pedagogia Crítica freireana, assim como outras concepções epistemológicas que aprofundam ou ampliam discussões propostas nesse paradigma de Educação.

Além dessas duas, apresentamos a seguir (Quadro 1) outras atividades, também ancoradas na perspectiva dos Letramentos Críticos, que estão sendo produzidas atualmente em um curso online de formação com educadores(as) de diversos níveis, modalidades, realidades educacionais e regiões do Brasil.

QUADRO 1: ATIVIDADES EM CONSTRUÇÃO NO ELO, २०२०.

\begin{tabular}{|c|c|}
\hline Tema & \begin{tabular}{c} 
Descrição \\
\hline $\begin{array}{c}\text { Representatividade } \\
\text { nas mídias sociais }\end{array}$
\end{tabular} $\begin{array}{c}\text { Chama a atenção para como mulheres são representadas em mídias sociais } \\
\text { (comerciais da indústria de cosméticos, por exemplo). Além disso, discute } \\
\text { apagamentos causados por uma visão estreita de mulher. }\end{array}$ \\
\hline Assédio nas ruas & $\begin{array}{c}\text { Problematiza assédio contra a mulher, isto é, como determinadas “cantadas”, ainda } \\
\text { que de brincadeira, podem instaurar algum tipo de violência, mesmo que simbólica. }\end{array}$ \\
\hline $\begin{array}{c}\text { Empoderamento } \\
\text { feminino }\end{array}$ & $\begin{array}{c}\text { Trata do empoderamento feminino. Discute, a partir de um videoclipe, de que forma } \\
\text { mulheres podem reagir diante da violência de gênero. Além disso, chama a atenção } \\
\text { para a questão da autoaceitação e do amor próprio. }\end{array}$ \\
\hline $\begin{array}{c}\text { Inclusão de pessoas } \\
\text { com deficiência }\end{array}$ & $\begin{array}{r}\text { Discute a inclusão de pessoas com deficiência. No decorrer de seus módulos, destaca } \\
\text { algumas barreiras que essas pessoas costumam enfrentar em seu dia a dia, bem como } \\
\text { alternativas para transformar essa realidade. }\end{array}$ \\
\hline $\begin{array}{c}\text { Desafios das mulheres } \\
\text { indígenas }\end{array}$ & $\begin{array}{c}\text { Chama a atenção desafios das mulheres indígenas no mundo de hoje. Além disso, } \\
\text { coloca em destaque mulheres indígenas que romperam com as expectativas de uma } \\
\text { sociedade capitalista, colonialista e patriarcal. }\end{array}$ \\
\hline
\end{tabular}


conclusão

\begin{tabular}{|c|c|}
\hline $\begin{array}{c}\text { Tema } \\
\begin{array}{c}\text { Estereótipos de beleza } \\
\text { feminina }\end{array}\end{array}$ & $\begin{array}{c}\text { Coloca em destaque os estereótipos de beleza feminina em obras de arte, campanhas } \\
\text { publicitárias e outras práticas sociais multimodais. Essa atividade visa salientar que } \\
\text { não existe um padrão de mulher bonita, uma vez que a beleza feminina reside na } \\
\text { diversidade de características, modos de atuar etc. }\end{array}$ \\
\hline Ciberassédio & $\begin{array}{c}\text { Trata das práticas de assédio no ciberespaço. Nesse sentido, discute o conceito de } \\
\text { ciberassédio, resumidamente definido como uma forma de violência praticada contra } \\
\text { alguém na esfera virtual. }\end{array}$ \\
\hline $\begin{array}{c}\text { O impacto do } \\
\text { agronegócio no meio } \\
\text { ambiente }\end{array}$ & $\begin{array}{c}\text { Discute de que forma certas práticas associadas ao agronegócio - tais como o uso de } \\
\text { agrotóxicos, por exemplo - podem trazer danos à saúde e ao meio ambiente. Além } \\
\text { disso, apresenta alternativas frente ao problema que é instaurado na atividade. }\end{array}$ \\
\hline Falsas notícias & $\begin{array}{c}\text { Problematiza o impacto das “falsas notícias” no mundo em que vivemos: o que são, } \\
\text { com que finalidade são produzidas, a favor de quem, contra quem, como podemos } \\
\text { identificá-las, entre outros aspectos. }\end{array}$ \\
\hline
\end{tabular}

FONTE: OS AUTORES, २०20.

Embora ainda não concluídas, as atividades apresentadas no Quadro 1 já estão disponíveis no ELO para uso e/ou adaptação, uma vez que possuem licenças de aberturas (licença Creative Commons ${ }^{8}$ BY-NC) que permitem modificações. Este é, também, um aspecto importante dos recursos didáticos disponíveis no ciberespaço: muitos deles já estão - e outros ainda podem vir a ser - licenciados de modo a permitir a adaptação e a personalização de recursos, o que interpretamos como freireano em pelo menos três aspectos.

Um primeiro aspecto em que essa abertura e maleabilidade de recursos no ciberespaço mostram-se freireanas diz respeito à possibilidade de adaptação para fins didático-pedagógicos. Em outras palavras, um recurso pode ser modificado de modo a contribuir e fazer sentido no contexto do(a) aprendiz, a partir da abordagem do(a) educador(a), que atua na direção de colaborar com a construção de saberes significativos e críticos que partam da realidade daquele(a) aprendiz.

Um segundo aspecto é concernente aos Letramentos Críticos, atrelados às linguagens e suas tecnologias, e não apenas restritos ao trabalho docente nas disciplinas típicas de "línguas”. Os Letramentos Críticos podem servir como abordagem teórico-metodológica de qualquer área, por seu prisma transdisciplinar, ou indisciplinar (BEVILÁQUA; COSTA; FIALHO, 2017). De tal forma, o ensino de geografia, matemática, biologia, artes, filosofia, química e sociologia, bem como o ensino de qualquer outra área, podem vincular-se ao mundo, à vida, onde os saberes não estão fragmentados e compartimentados, mas sim conectados, em fluxo vital.

Finalmente, um terceiro aspecto de aproximação entre os recursos digitais e o legado freireano, em nossa leitura, diz respeito à possibilidade de adaptar uma atividade, um módulo ou um material para o ensino que não tenha sido pensado na lógica dos Letramentos Críticos para vinculá-lo a tal abordagem. Um material didático que não foi pensado para um trabalho didático à luz dos Letramentos Críticos (BEVILÁQUA, 2017) pode vir a ser reformulado para incorporar tais pressupostos teórico-metodológicos. Por sua abertura, tais recursos podem ser adaptados para servir a um ensino no viés da Pedagogia Crítica e dos Letramentos Críticos.

\section{CONSIDERAÇÕES FINAIS}

O presente artigo foi produzido em concomitante com o desenvolvimento, a organização e o lançamento da Coleção Paulo Freire Hoje, conjunto de obras cujo escopo é, especificamente, explicitar a atualidade do pensamento freireano no que tange a variados temas, reinventados a partir das atuais demandas da educação contemporânea. O volume Paulo Freire na Cibercultura (COSTA et al., 2020b)

\footnotetext{
${ }^{8}$ Para saber mais sobre as licenças CC, ver Beviláqua (2017), ou visitar o website Creative Commons Brasil: <https:// br.creativecommons.org/>.
} 
é um dos primeiros lançamentos da referida coleção e, nele, são tecidas reflexões sobre as tecnologias digitais que temos hoje ao alcance de educadores e educadoras.

Ademais, este artigo foi produzido também nestes tempos de implementação emergencial do ensino remoto em função do novo Coronavírus SARS-CoV-2 (Covid-19) Covid-19, que demanda de docentes e aprendizes letramentos digitais de variadas ordens e adaptações significativas de suas práticas de ensino e aprendizagem no ciberespaço, quando possível (a considerar a notória desigualdade social do país). O cenário atual de pandemia causada pela Covid-19 parece alargar nossas incertezas sobre a educação online, mas não diminui a necessidade de nosso fazer pedagógico seguir alinhado a uma perspectiva freireana de docência, isto é, num viés de educação humanizadora, crítica e libertadora.

Nesse sentido, propomos o presente texto, que busca ilustrar a atualidade de Paulo Freire. Para tanto, não apenas revisitamos as concepções de tecnologia do Patrono da Educação Brasileira, mas fomos além: concordando com Freire sobre as tecnologias educacionais que, per se, não são nem boas, nem más, tampouco neutras, enfocamos a práxis tecnológica. Essa práxis demanda uma postura de constante curiosidade e criticidade frente aos usos de recursos tecnológicos, sobretudo no que concerne aos processos de ensino e de aprendizagem.

Também inspirados por Freire, seguimos a tendência desenhada pelo próprio Patrono da Educação Brasileira, décadas atrás, de pensar as tecnologias para mediar os processos educacionais no viés dos letramentos, sem que isso se resuma a uma alfabetização bancária, descontextualizada dos usos das linguagens e tecnologias em prol de uma ética maior (BEVILÁQUA, 2017). Queremos dizer, com isso, que se mostra urgente fazer uso de tecnologias para expandir a capacidade crítica dos aprendizes, semelhante ao que já fazia Freire ao alfabetizar numa perspectiva que, hoje, convencionamos designar como Letramentos Críticos.

Nesse mesmo sentido, desejamos que as tecnologias em rede sejam empregadas na produção, na composição, no armazenamento e no compartilhamento de materiais e atividades didáticas na perspectiva da Pedagogia Crítica e dos Letramentos Críticos (BEVILÁQUA, 2017; COSTA et al., 2020b), sempre pensando a educação como instrumento (tecnologia) de libertação. A considerar que as tecnologias nunca são neutras, elas não devem ser empregadas com abordagens pedagógicas ditas neutras (que, a bem da verdade, não existem!), mas com abordagens teórico-metodológicas que questionem as opressões, as violências e as injustiças do mundo, como a abordagem dos Letramentos Críticos. Por isso, investimos na apresentação de exemplos práticos de recursos digitais disponíveis na Web produzidos a partir de letramentos digitais e no viés dos Letramentos Críticos. Tais exemplos, por um lado, indicam que materiais didáticos críticos disponíveis online mantêm vivo e atual o legado freireano, e, por outro lado, mostram que a tecnologia pode, sim, servir como potente instrumento de mediação de uma educação libertadora.

\section{REFERÊNCIAS}

ALENCAR, Anderson Fernandes de. O pensamento de Paulo Freire sobre a tecnologia: traçando novas perspectivas. V Colóquio Internacional Paulo Freire. Recife, Pernambuco. 2005. Anais. Disponível em: https://docplayer.com.br/16407780-O-pensamento-de-paulo-freire-sobre-a-tecnologiatracando-novas-perspectivas.html. Acesso em 27 de jul. de 2019.

BEVILÁQUA, A. F. Linguagens e tecnologias a serviço de uma Ética Maior: a produção de Recursos Educacionais Abertos na perspectiva dos Letramentos Críticos. 2017. (Dissertação de Mestrado em Linguística Aplicada) - UCPel: Rio Grande do Sul, 2017.

BEVILÁQUA, A. F.; COSTA, A. R.; FIALHO, V. R. O poder está no touch: produção de Recursos Educacionais Abertos na perspectiva dos Letramentos Críticos. In: CARDOSO, R. M. et al. (Org.). Tendências contemporâneas na pesquisa em Linguística e Literatura: Rede Sul Letras. Campinas: Pontes, 2019, p. 308-324.

BRAVERMAN, H. Labor and Monopoly Capital: The Degradation of Work in the Twentieth Century. New York and London: Monthly Review Press. 1974. 
CALADO, A. J. F. Paulo Freire: sua visão de mundo, de homem e de sociedade. Caruaru: FAFICA, 2001.

CASSANY, D.; CASSTELLÀ, J. Aproximación a la Literacidad Crítica. Perspectiva, Florianópolis, v. 28, n. 2, p. 353-374, jul. 2010.

CORTELLA, M. S. Paulo Freire: um pensamento clássico e atual. Revista e-Curriculum, São Paulo, v. 7, p. 1-14, 2011. Disponível em: https://revistas.pucsp.br/curriculum/article/view/7590. Acesso em 19 de mai. de 2020.

COSTA, A. R. A Educação Popular em contexto Pré-Vestibular uma vez mais em debate: há Alternativa! XVII Fórum de Estudos: Leituras de Paulo Freire. Santa Maria, Rio Grande do Sul. 2015. Anais. Disponível em: https://drive.google.com/file/d/1wFYnZtFUpWdlsi2pLb762IJX20K0aPEj/ view. Acesso em 22 de jun. de 2020.

COSTA, A. R.; FIALHO, V. R.; BEVILÁQUA, A. F.; OLIVEIRA, E. 10 anos de Jornada de Elaboração de Materiais, Tecnologia e Aprendizagem de Línguas: Estado da Arte. In: LEFFA; V. J.; FIALHO, V. R.; BEVILÁQUA, A. F.; COSTA, A. R. (Org.) Tecnologias e ensino de línguas: uma década de pesquisa em Linguística Aplicada. Santa Cruz do Sul: EDUNISC, 2020a, v. 1, p. 19-43.

COSTA, A. R.; BEVILÁQUA, A. F.; KIELING, H. S.; FIALHO, V. R. Paulo Freire hoje na Cibercultura. Porto Alegre: Editora CirKula, 2020b. 100p.

COSTA, A. R.; GOMES, T. F. Contribuições da obra de Paulo Freire nos Encontros de Cursos PréUniversitários Populares: redes de indignação e esperança. Revista de Educação Popular, v. 16, p. 137-151, 2017.

COSTA, A. R.; GOMES, T. F. De Paulo Freire aos cursos populares: questões históricas e desafios contemporâneos. Saarbrücken: Novas Edições Acadêmicas, 2018. 100p.

DURRANT, C.; GREEN, B. Literacy and the new technologies in school education: meeting the L(IT) eracy Challenge? In: FEHRING, H.; GREEN, P. Critical Literacy. Australia: Internacional Reading Association, 2001.

FAIRCLOUGH, N. El análisis crítico del discurso y la mercantilización del discurso público: las universidades. Tradução Elsa Ghio. Discurso \& Sociedad, v. 2, n. 1, p. 170-186, 2008.

FERREIRA, A. J. Formação de professores: raça/etnia. Cascavel: Coluna do Saber. 2006.

FERREIRA, A. J. Teoria Racial Crítica e Letramento Racial Crítico: Narrativas e Contranarrativas de Identidade Racial de Professores de Línguas. Revista da Associação Brasileira de Pesquisadores(as) Negros(as) - ABPN, v. 6, p. 236-263, 2014.

FREIRE, P. A Educação na Cidade. São Paulo: Cortez, 1995.

FREIRE, P. A importância do ato de ler: em três artigos que se complementam. São Paulo: Cortez, 1989.

FREIRE, P. A máquina está a serviço de quem? Revista BITS, p. 6, maio de 1984.

FREIRE, P. Ação cultural para a liberdade e outros escritos. Tradução: Claudia Schilling. Rio de Janeiro: Paz e Terra, 1968.

FREIRE, P. Cartas a Guiné-Bissau: registros de um a experiência em processo. Rio de Janeiro: Paz e Terra, 1977.

FREIRE, P. Educação e Mudança. Rio de Janeiro: Paz e Terra, 1976. 
FREIRE, P. Pedagogia da Esperança. Um reencontro com a Pedagogia do Oprimido. Rio de Janeiro: Paz e Terra, 1992.

FREIRE, P. Pedagogia da Indignação. Cartas pedagógicas e outros escritos. São Paulo: UNESP, 2000.

FREIRE, P. Pedagogia da Autonomia: Saberes necessários à prática educativa. São Paulo: Paz e Terra. Coleção Leitura. 1996.

FREIRE, P; PASSETTI, E. Conversação Libertária com Paulo Freire. São Paulo: Imaginário, 19941995.

KUMARAVADIVELU, B. TESOL methods: changing tracks, challenging trends. TESOL Quarterly, v. 40, n. 1, p. 59-81, mar. 2006.

LEFFA, V. J. Uma outra aprendizagem é possível: colaboração em massa, Recursos Educacionais Abertos e ensino de línguas. Trabalhos em Linguística Aplicada, v. 55, n. 2, p.353-378, ago. 2016.

LÉVY, P. Cibercultura. Rio de Janeiro: Editora 34, 2010.

PINTO, C. M. Metanálise qualitativa de investigação brasileira sobre Letramento Digital na formação de professores de línguas do RS. 2015. (Tese de Doutorado em Letras) - UCPel: Rio Grande do Sul, 2015.

SOARES, M. B. Letramento e alfabetização: as muitas facetas. Revista Brasileira de Educação, Rio de Janeiro, v. 1, n. 25, p.5-17, abr. 2004.

URZEDA-FREITAS, M. T. Educando para transgredir: reflexões sobre o ensino crítico de línguas estrangeiras/inglês. Trabalhos em Linguística Aplicada, v. 51, n. 1, 2012, p. 77-97, 2012. 